degenerative change, and because they suggest the probability that in all cases of confusion and stupor there is pressure from an increased amount of fluid in the lateral ventricles; while in the cases that are disturbed the fluid is probably over the convexity.

In my experience inhibition and incoordination occur only in those cases in which the degeneration is primary and begins during adolescence, that is, when degeneration begins before development is complete. In these individuals the higher functions of the brain are necessarily imperfectly developed, with the consequence that coordination and direction are not completely organized. Therefore, anything that lowers vitality may put these functions in abeyance, and leave inhibition dominant, just as in the normal individual unusual and untoward conditions may operate to produce the same result in the undeveloped and inexperienced.

\section{IMPERFORATION OF THE LACHRYMONASAL DUCT IN THE NEW-BORN, AND ITS ĊLIN-} ICAL MANIFESTATIONS.*

\section{WILLIAM ZENTMAYER, M.D. PHILADELPHIA.}

The common clinical manifestation of cbstruction to the lachrymonasal duct in the new-born has been usually described under the term "congenital dacryocystitis," a very unsatisfactory one as a cystitis is not usually present, and when present is of secondary origin. Jackson ${ }^{1}$ has recently written on the subject under the title of "Delayed Development of the Lachrymal-nasal Duct." an entirely proper term, in a restricted sense, but not intended to cover all the conditions which may give rise to the symptoms of so-called congenital dacryocystitis.

Until the appearance of the paper of Peters ${ }^{2}$ but little consideration had been given this interesting and important subject and it is only within the past decade that frequent references to it are to be found in literature. Few of these are by American authors, and these mostly within the past three or four years. Historically, it is of interest to note that in the first edition of the Graefe-Sämisch Handbuch, Schirmer states that until Critchett published his cases, infants at the breast were considered exempt from dacryocystitis (Kipp). Kipp ${ }^{3}$ says his statistics show that 10 per cent. of all cases of dacryocystitis, among which were several cases of phlegmon of the sac, occurred in children, under 1 year of age. But it was not until the appearance of the paper of Peters that the subject was broadly considered, and a causal relationship established between the clinical phenomena and the developmental peculiarities of the lachrymal passages. The investigations of RochonDuvigneaud, ${ }^{4}$ Vlacovitch, ${ }^{5}$ Stanculeanu, ${ }^{6}$ and others, established from anatomic research the existence of structural abnormalities as well as delayed development as causes.

As it is the author's purpose to present principally the clinical side of the subject and to emphasize the method of treatment which he considers best meets the indica-

* Read in the Section on Ophthalmology of the American Medical Association, at the Fifty-ninth Annual Session, held at Chicago June, 1908

1. Ophth. Rec., July, 1907 .

2. Klin. Monatsbl. f. Augenheilk. ; also Ztschr. f. Augenheilk., 1899.

3. Trans. Am. Ophth. Soc., N. Y., 1879.

4. Arch. d'ophth., February, 1899 ; February, 1900

5. Beitr. z. Augenl., 1892 (Nagel's Jahresb., i1).

6. Arch. dophth., February, 1900. tions, no extended account of the embryology of the tear passages will be given.

\section{EMBRYOLOGY.}

The accepted view of the development of the lachrymonasal canal is that in the young fetus there exists a groove between the external nasal, the frontonasal and the maxillary processes, extending from the eye to the outer border of the nasal opening. The nasal duct arises as a thickening of the epidermis along the line of the lachrymonasal groove. This forms a solid ridge, which separates, except at each end, and forms a solid cord (Ryder). This cord becomes converted into a canal by a separation of the epithelial cells. The resulting débris, up until the seventh month or later, fills the canal with a gelatinous mass.

\section{ETIOLOGY.}

The possible causes of the condition manifesting itself as a discharge from the puncti, a distention of the sac or an abscess in the new-born are sixfold: (1). Delayed separation and necrosis of the epithelial cells forming the cord from which the canal is formed. (2) Retention of the separated cells through imperforation of the septum between the lachrymonasal duct and the nasal chamber. (3) Through obstruction due to annular folds of the mucous membrane which may form at any point within the duct, Huschke's and Hasner's valves. (4) Faulty development of the cartilages (D. ( runn $^{7}$ ). (5) Partial occlusion by pressure of inferior turbinate. (6) Stenosis from pressure exerted on the bones of the face during instrumental labor. (The last group is a suppositional one, suggested by Peters' observation that in one of his cases there were marks of the forceps over the nose on the side corresponding to the discharge from the punctum.)

The majority of the cases doubtless fall under the second group, as here the cause is one for which the anatomic possibility exists in every fetus. It would seem probable that this affection might be found proportionately more frequently in the prematurely born as the septum is usually present until shortly before birth, but Stanculeanu ${ }^{8}$ found the condition of so-called congenital dacryocystitis present only four times in twenty embryos at the seventh month, the period previous to which, according to this writer, the lachrymonasal duct is never patulous. He believes that this observation overthrows the classical theory as to the pathogenesis of this condition. He was, however, unable to demonstrate an infection to explain the cases that he did observe; but Rochon-Duvigneaud ${ }^{4}$ holds that to produce this condition there must be an exaggerated proliferation of the epithelium of the canal. Morax believes that infection first takes place after the birth of the child, and therefore considers the term "congenital dacryocystitis" incorrect.

\section{COMPLICATIONS.}

A distention forming a diverticulum at the lower part of the sac is an associated condition, the presence of which, often suspected from the clinical phenomena (Vossius, ${ }^{8}$ D. Gunn, ${ }^{7}$ Addario) has now been demonstrated in section by more than one investigator (Rochon-Duvigneaud, ${ }^{4}$ Vossius $^{8}$ ). This abnormality may be due to a faulty development, or as is more often the case, by distention of the duct by retained epithelial débris and mucous secretion. The latter, as pointed out

7. Ophth. Rev.. Februarv, 1900.

8. Beitr. z. Augenh., 1,1891 . 
by Bochdalek, forming a consistent mass, may, in itself, obstruct the lumen of the canal and hinder egress to the nose. Mayou ${ }^{9}$ has shown that throughout development the lower end of the lachrymal duct is extremely small and remains so at birth, being partially occluded by pressure of the inferior turbinate bone. That a catarrhal or even purulent conjunctivitis may be excited by the contents of the lachrymal sac was demonstrated by Ollendorff's ${ }^{10}$ cases and by the cases of Gunn,; where the inflammation of this membrane at once subsided when the duct was made patulous.

Lachrymal abscess figures as a sequel to atresia of the duct. D. Gunn ${ }^{7}$ has seen five eases of this nature in infants ranging in age from nine days to six months, in which the method and result of treatment left no doubt as to the origin. Mayou ${ }^{\ominus}$ has treated eight cases occurring in the first few weeks of life the result of secondary infection from ophthalmia neonatorum or from organisms which may gain entrance to the lachrymal sac. Yan Duyse, ${ }^{11}$ Selenkowsky ${ }^{12}$ and others record like cases.

\section{SYMPTOMATOLOGY.}

It needs but a brief chapter wherein to describe the symptoms by which congenital obstruction of the lachrymonasal duct presents itself. Immediately, or within a few days after the birth of the child, a small amount of white or yellowish-white discharge is noticeable at the inner angle of the eye. The conjunctiva is usually normal, or but slightly injected. There may or may not be fulness over the sac. Pressure applied over this region may cause a gelatinous white fluid to exude from the punctum. If there has been distention, the pressure may cause the fulness to disappear, accompanied or not by a discharge from the puncti or from the nose. In some instances there is associated a catarrhal eonjunctivitis, which occasionally takes on a purulent type.

If proper treatment is withheld, under the influence of winking, the conjunctival secretions penetrate and infeet the gelatinous contents of the sac and excite an inflammation whieh may continue as a subacute condition or kindle an acute process.

The affection is rery rarely bilateral.

\section{BACTERIOLOGY.}

As might well be expected from the circumstances, a great variety of micro-organisms have been found in the secretion. Merconti ${ }^{13}$ saw a bacillus resembling the coli communis. The gonococcus of Neisser was found by Antonelli ${ }^{14}$ and Mayou, ${ }^{9}$ the pneumococeus by Hirsch ${ }^{15}$ and the Staphylococcus pyogenes aureus by Selenkowsky, ${ }^{12}$ and the Morax-Axenfeld bacillus by Mayou. Ball ${ }^{16}$ states that the xerosis bacillus, the pneumobacillus and the Bacillus fetidus ozena have all been found.

\section{PROGNOASIS.}

This is undoubtedly good in a great majority of instances, as it has been shown that in those cases where there is either an incompletion of the cleaning up process or an imperforation of the thin diaphragm at the inferior meatus, Nature, in time,carrects the trouble; but at any stage in the process, infection of the contents of the canal may determine an inflammatory process,

9. Ray. London Ophth. Hasp. Rep, xvil, 246, January, 1908.

10. Ophth. Klin., Jan. 20.1907.

11. Ann. Soc. đe méd. de Giand. 1892, 1xxi, 11-19.

12. Vestnfk oftalmol., xix. No. 1.

12. Vestnfk oftamal., xix. No. 1. . Atti d. r. Aecad. d. fisiocrit. di Siena, 189?.

14. Quoted by Vossius. Ann. de méd. et chir. inf., 1905.

15. Arch. Ophth., 1907, xxxvii, 61.

16. Modern Ophthakmology. leading to abscess formation, if immediate drainage into the nose is not secured. An injury to the cornea, or a marasmic ulceration of the cornea, might endanger the safety of the eye, as evidenced by Selenkowsky's case of phlegmon of the tear sac in the new-borm in which the $S$. pyogenes aureus, of a highly virulent type, was present in large numbers. Purvlent conjunctivitis may be set up by infection.

Considering that one careful observer has found that 25 per cent. of his cases of dacryocystitis occurred before the tenth year, it is likely that chronic daeryocystitis in the child may be looked on as a possible sequel to the congenital obstruction.

\section{DIAGNOSIS.}

To those familiar with the occurrence of the affection, its diagnosis presents no difficulties; but to the general practitioner, alert to possible occurrence of gonococcal conjunctivitis, the presence of a white secretion in the eye, just after birth, is a disturbing symptom. The absence of inflammatory phenomena, with puffiness of the lids, the benignity of the course, the usual monolateral development, and the scantiness of the discharge, should ease his mind, and if it does not, a microscopic examination of the discharge would.

Terson $^{17}$ has seen in a prematurely born, but well dereloped female child, a hemispherical fluctuating tumor, of about the size of a hazelnut, overlying the right lachrymal sac. It was absolutely irreducible and unattached to the skin. The nature of the cyst was problematic. According to Terson, the possibility of such a tumor being a meningocele, an encephalocele, or of the nature of a true prelachrymal serous or fatty cyst, must be borne in mind. The elder Terson removed from an adult the anterior portion of a prelachrymal cyst which was entirely independent of the healthy lachrymal passages, yet proved, histologically, to be made up of tissuc normal to the lachrymal sac.

According to 'Terson the differential diagnosis between prelachrymal cysts of various kinds, and so-called congenital dacryocystitis is extremely difficult. In certain cases it must rest entirely on the irreducibility of the tumor.

\section{TREATMENT.}

Varied opinions are held concerning the proper management of these cases. Some surgeons (Weeks, ${ }^{18}$ Jackson, ${ }^{1}$ Peters, ${ }^{2}$ Panas, Terson, ${ }^{17}$ Valude ${ }^{19}$ and others), believing that as the condition is one which, in the vast majority of instances, will correct itself in time, presumably without exciting any secondary disturbance, advise a simple collyrium, the use of solutions of silver, of pressure, and massage, until Nature has asserted herself, or for several months before employing operative procedures, Ollendorff, ${ }^{10}$ Koster, ${ }^{20}$ Cutler, ${ }^{21}$ RochonDuvigneaud, ${ }^{4}$ Parsons, ${ }^{22}$ Bochdalek, Mayou and others ${ }^{2: 3}$ employ probing or syringing. Peters has, at times, used probes. Parsons, who holds a decided opinion as to the injurious effect of probing in the adult, apparently makes an exception in treating this affection in the young, as he states that a single probing usually brings

17. Arch. méd. de Tonkuse, 1904. :306-310

18. The Journal A. M. A., Dec. 10.1904, p. 1760 .

19. Bull. Soc. de pediat. de Paris, $18 \%$, i.

20. Graefe's Areh. Nov. 5, 1905.

21. Arch of Ophth. Nay, 1903.

22. Brit. Med. Jour., Feb, 93,1907

23. Fejer: Arch. f Augenheilk. February, 1907: Rabinorich Rusk Vrach. St. Petersb., 1902, i, 1206-1208: Kamneff : Vrach. Gaz.. St. Petersb., 1902. ix, 29: Levy : Paris Thesis : .Jemsolinski : Vestnik oftalmol., 1903, xx; Pechfn: Arch. dophth., 1005. 
about a cure. Mayou ${ }^{9}$ believes that aspiration fails to clear the duct when there is congenital narrowing, and says that this view is further borne out by the clinical fact that, if one of these patients "is seen before an abscess forms, one careful passage of a probe is generally sufficient to effect a cure." Jackson, in quoting Weeks'1s advice simply to cleanse the conjunctival sac and protect the parts until Nature has had a fair opportunity to establish a passage, and if this has not occurred at the end of two months to slit the canaliculus slightly and pass a small Bowman probe, states that he would not limit to two months, or even six months, the period in which it is proper to try milder measures, provided the symptoms are controlled by such treatment.

A successful method, not recommended by any writer, was witnessed by Copez. According to Van Duyse, ${ }^{11}$ this author saw a lachrymal tumor rapidly cured by the nurse applying mouth suction to the nose of the infant.

As the possible results of delayed opening of the tear passages may be the occurrence of infection, with its usual sequelæ and dangers, it does not seem to the author a wise procedure to wait on Nature an indefinite period to eliminate this menace; especially as the therapeutic measures advised in the palliative treatment include the continued use of organic salts of silver at home, thus adding to the former dangers the one of argyrosis, the use of massage, a measure to which Ollendorff ${ }^{10}$ ascribes the blame for the occurrence of necrosis in one of his cases; also, seemingly, disturbance of the nutrition of the infant (Cutler' ${ }^{21}$ ).

No doubt the danger of allowing Nature to effect the cure would be slight if the patient could be kept under constant supervision, but this is rarely possible, especially when the treatment may be giving no tangible results.

As it seems to be the practice of some of these clinicians to use probes to overcome the obstruction when the expectant treatment has failed, it would appear to me that some such procedure is indicated at once, when simple pressure over the sac fails to give permanent relief. Maternal pride shrinks from displaying a pussy-eyed infant to the critical public, and the author has received from no one more grateful thanks than he did from a mother whose infant had been treated expectantly for weeks, and was at once cured by probing.

The result secured by probing in the first case of my series was so brilliant that I pursued the same course in my subsequent cases, and, with one exception, with the same success, namely, disappearance of the trouble after a single probing. In the exceptional instance it was necessary to repeat the probing three times.

Doubtless, for those unaccustomed to passing probes, it would be wiser to counsel measures requiring less skill. For this reason, syringing has been recommended by some, and while it is possible in some cases to force a passage in this way, it does not seem to me to be less difficult than probing, unless the baby be etherized, a measure which $\bar{I}$ have found unnecessary in passing probes.

Probing here is done under different circumstances from those in lachrymal obstruction in the adult. As a rule, no resistance is met with, and the probe readily follows the natural passage, which, according to Mayou, ${ }^{9}$ is inclined much more backward than it is in the adult. a probe making an angle of about 45 degrees with the forehead when passed through the duct.

\section{DISCUSSION.}

Dr. EDward Jackson, Denver: The classification given under the heading of etiology covers the ground thoroughly. But if we consider the lachrymal passages in general, including the adjoining bony and cartilaginous structures as well as the soft parts, all of the causes enumerated, except the conjectural one of pressure of the face during instrumental labor, would be included in faults of development of the passages. Generally the fault is merely a delay in reaching normal development. Failure to develop a lumen, converting the rod of epithelium, which generally marks the site of the lachrymal passages, into a tube, might occur at any point. Most frequently it occurs at the nasal end of the passage; but probably in an important proportion of cases it is one of the socalled valves that fails to become pervious. Some such structures are generally present at some stage of development, but mostly they become pervious before the lachrymonasal sejtum.

The condition is most likely to be confused with conjunctivitis in the new-born; not with gonococcus conjunctivitis, but with certain subacute or chronic forms that are not rare. In these cases of conjunctivitis the discharge is whitish or gray, the conjunctival sac is likely to present some accumulation of tears, and the persistence of the condition is quite suggestive of lachrymal disease. One is scarcely justified in making the diagnosis of lachrymal obstruction in the new-born unless there is actual evidence of accumulation in the sac and regurgitation of the matter on pressure.

Knowing, as we do, the strong tendency to continued development of the passages and the probability of ultimately securing in these cases completely normal lachrymal apparatus in the end, without operative interference, I watch for complications, and so long as they do not arise avoid any operative interference other than frequent gentle pressure over the lachrymal sac. I have not seen any case of staining from silver salts in infants; but the use of silver preparations is not a necessary part in the expectant treatment of infantile lachrymal obstruction. Solutions of boric acid or sodium chlorid used to cleanse the eye at frequent intervals probably serve the purpose equally well. It is but right that the parents of an infant presenting this condition should be fully informed of the nature and probabilities of the case, and allowed to choose whether or not any operative measure should be resorted to. At the same time they should be informed that the condition could probably be relieved by a simple probing, and that complications might arise which would render operation urgent. When meehanical interference is to be resorted to $I$ prefer the passage of a probe of moderate size through the temporarily dilated punctum. This is not wholly without risk even in skilful hands, but the risk from attempting to force a passage with fluid from a syringe is at least equally great. Syringing has been looked on as quite safe and conservative, but the permanent staining of the skin by argyrol and the orbital cellulitis with optic nerve atrophy, which have been reported after syringing the lachrymal passages are serious possibilities. The risk of mechanical injury at the time of treatment seems quite as great with the syringe as with the lachrymal probe.

DR. S. L. ZIEGLer, Philadelphia: I think that these cases of congenital occlusion of the duct are sufficiently rare so that we should place on record any that we may have seen. In twenty years I can recall having treated only two cases. The first was a case of dacryocystitis which occurred between the first and second months. There was no involvement other than the dacryocystitis with mucopurulent discharge. The valve of Hasner was probably closed, thus preventing the passage of tears down into the nose. The case occurred fifteen years ago, and I have had occasion to see the young girl within the past year. She has had no further trouble. My treatment at that time was a single rapid dilatation of the duct, which was practically all the treatment that the child had. The second was a case of atresia with epiphora, in which no remedial measures would bring about a passage of the tears. This case was also promptly relieved by rapid dilatation. The parents bring these children to us for relief, 
and if this is not promptly obtained by remedial measures I think that the question of dilatation is quite within the bounds of conservative : surgery.

DR. C. J. KIPp, Newark: I wrote on this subject twentynine years ago and am surprised to hear the last speaker say he has seen so few cases. I see cases at least once a month. They come as cases of ophthalmia limited to one eye. In all cases treated within the last ten years I have used simply cleansing and pressure and have not had to use a probe in ant ease. The cases that come with abscess of the lachrymal sae are those that have been probed by other oeulists. Cases that come to me within a couple of weeks after birth are cured in a very short time by simple eleansing and pressure. You must instruct the nurse or mother to exert pressure properly to direct the secretions downward. If you do it yourself you can often feel the obstruction give way. I think that the best plan, even for a skilful oculist, is to avoid probing. You can get along without it. Of course, it makes more of an impression on the mother and friends to use the probe, but it is more benefieial to the patient to use the finger.

Dr. Frram Woons. Baltinore: I recall four cases that I have followed very closely. One got well without any treatment whatever. It was simply treated on the expectant plan, expressing the secretion and cleansing, and in two months the whole thing disappeared. The other cases were treated by probing under anesthesia. In two cases one single probing effected the cure. In one of the eases a diffienlty arose in getting a probe down into the nose. The small No. 2 Bowman passed a short distance, then stopped, and it was impossible, without exerting more pressure than I cared to use, to introduce it further. It occurred to me that the difficulty might be a catarrhal swelling of the mucots membrane. After two weeks of waiting a third attempt took the probe directly into the nasal cavity without effort and the case has remained well now for six months. I think that it is extremely important to realize in the introduction of probes into the infant lachrymal dict that when mueous secretion has persisted there is possibility of a good deal of swelling in the lower end of the duet and rough manipulation may do a good deal of harm.

Dr. W. Zentmayer, Philadelphia: In my first ease the patient had been treated by a local ophthalmologist for eatarrhal conjunctivitis. An immediate cure followed the passing of a probe. It was the gratitude of the mother in this ease that caused me to pursue the treatment advocated in my paper in subsequent cases. It is very unpleasant for a mother to have an infant with a purulent eye to show her friends and she is grateful for having it cured by a single treatment. Dr. Jackson. says that he would treat a member of his own family in the expectant manner. So would $I$, because I should have the patient under constant obserration. In practice this is not possible, and if the treatment is giving no results, the patient is apt to be neglected and serious trouble may supervene. In the Rostock elinic and in the private practice of Professor Peters. but seventeen eases were observed between 1901 and 1908; so that the condition can not be considered a common one. Mayou, whose experience has been large, states that if these cases be seen before an abscess forms one careful passage of a probe is generally sufficient to effect a cure. Dr. Woods' diffieulty in passing a probe in his case may have been due to that condition referred to in the fifth division of the etiology, "partial ocelusion by pressure of the inferior turbinkte bone."

The Ocular Tuberculin Reaction.-E. Waldstein in the Prag. med. Wehnsehr., Feb. 27, 1908, xxxiii, 9, warns against the use of the tuberenlin oeular test in eases in which disease of the conjunetiva exists. He says that the reaction in steh cases is mueh more severe than in sound eyes and may cause ineonvenient results. The curaneous method of von Pirquet, in which a healthy skin is expressly stipulated, is therefore preferable as it in no way endangers the nealth of the patient, while the conjunctival reaction often extends beyond the desired limits and sometimes causes permanent lesions

\section{THE CORREEATION OF CLINICIAN, PATII-} OLOGIST AND LAYMAN.*

\author{
BOND STOW, A.M., M.D. \\ Pathologist, Metropolitan Hospital, Blackwell's Island. \\ NEW YORK.
}

Medicine has two fundamental objects in view, of equal and vital importance: first, the immediate relief of human suffering and the restoration of the individual to his normal standard of health; second, the protection and maintenance of the members of society in this normal state. The first strictly concerns the clinician, the second the hygienist.

Hygiene, although strictly founded on scientific medical data, nevertheless, so intimately is associated with many intricate sociologic problems that we recognize it as a science distinct and apart from medicine in its more restricted significance.

I wish to center your thought more particularly on clinical medicine or that intimate association between physician and patient in the diagnosis and treatrent of disease, as well as to point out the inestimable service rendered both laity and the profession by the pathologist, the clinician's inseparable companion.

Virchow recognized the clinician as the close and confidential agent of the pathologist, as it is he who garners the data from life which the latter is to combine with those of his studies as he forges the chain of our understanding of morbid phenomena. The clinician must guard the truth and accuracy of his findings as carefully as the pathologist does the facts elicited by his work, so that when these combined data are received in the final summing up of the evidence the conclusions to be drawn therefrom shall rest on trustworthy premises.

The one can not be regarded as the superior of the other, for both reciprocally are dependent as they struggle in their respective spheres each to search out and collect the evidence which united deciphers Nature's hieroglyphics.

The clinician is often confronted with an array of symptoms as occult and intricate as the solution of a Chinese puzzle. It becomes his duty to separate the primary from the secondary symptoms. carefully to place each in its proper perspective, and therefrom logically to deduce a true conception of the actual underlying pathologic processes involved, for which he is to advise rational means that are to remove the cause and hence the effect. A comprehensive understanding of the etiology of disease, a vast bedsite experience, in conjunction with a thorough knowledge of the fundamental truths of pathology, compose the tripod on which he must stand before attempting to solve the mystery. Even then the task is not alwavs a simple one.

The clinician who is privileged to have his bedside conclusions reviewed by the pathologist is incleed fortunate, for thereby his errors become rectified, and after repeated humiliating disclosures stern necessity compels the cultivation of that spirit of intelligent criticism and conservatism so essential for mastery over the diffeult details of medical science.

But he who knows not the blessings of pathologic criticism may go on and on, year after year, committing the same error over and over again because of the lack of this acquaintanceship with the pathologist, who, though oceasionally quite discomforting to an oversensitive soul, yet nevertheless remains the clinician's best

* Read before the Medical Society of the County of New York at its stated meeting, March 22,1908 . 